\title{
A study of post-menopausal breast abscesses in West Africa
}

W. I. B. Onuigbo*

\begin{abstract}
It is acknowledged that the highest incidence of breast abscess occurs in lactating women.

Methods; Between February 1970 and February 2000, 215 females with suspected breast abscess were biopsied by 97 doctors working in 34 hospitals attended by patients of the Igbo or Ibo ethnic group in Nigeria, West Africa. Their data were retrieved and analyzed.

Results: Their ages ranged from 11 to 78 years, averaged 40.5 years and peaked between 31 and 40 years. Breast abscess was seen in 53 of them.

Conclusion: Breast abscess is common $(22.3 \%)$ in post-menopausal Igbo patients aged over 50 years.
\end{abstract}

Key words: fibroadenoma, tumour, mammary, dysplasia, galactocele.

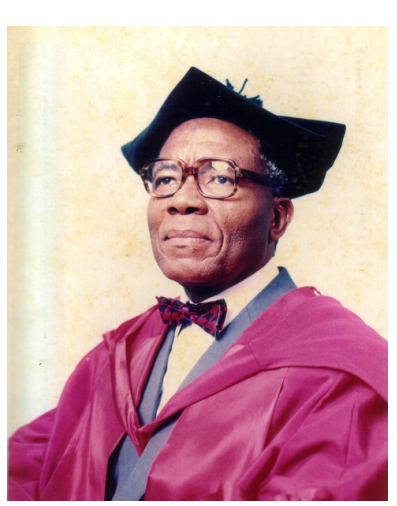

$\mathrm{E}$ lsewhere, the author drew attention to the significance of reprint requests in medical research ${ }^{1}$. Here, he wishes to make use of one such reprint ${ }^{2}$ that was received in from the West Indies. That reprint dealt with the uncommon nature of the postmenopausal breast abscess. Therefore, it was deemed important to compare the West Indian findings with those emanating from West Africa, especially because it was from this continent that the West Indians mostly migrated. Moreover, such comparisons should point the way to research on this ailment in other parts of the world.

\section{Material and Methods:}

The surgical pathology records of breast diseases were among those kept at a Reference Pathology Laboratory situated in Enugu, the capital city of the Eastern Region of Nigeria. They were reviewed as regards all the cases diagnosed between February 1970 and February 2000 in respect of the Igbos or Ibos $^{3}$ who constitute a major ethnic group in Nigeria, West Africa.

* Medical Foundation and Clinic, 8 Nsukka Lane, P. O. Box 1792, Enugu, Nigeria 400001.e-mail. wilsonui@yahoo.com Tel.234-803-720-8680.
The relevant clinical details were extracted from the request forms that accompanied the surgical specimens while the pathological data were assembled from duplicate Laboratory Reports.

\section{Results:}

During the 30-year period of this study, 215 Igbo females presented with localized suspected breast abscesses to 97 doctors working in 34 hospitals. Their ages ranged from 11 to 78 years (average 40.5 years). Table 1 shows the overall age distribution pattern, the peak age being $31-40$ years. The menopausal status was often not recorded in the request forms, but it was mentioned in 4 patients aged below 51 years. However, we considered 52 [24.2\%] ladys above 50 year as postmenoposal.

Table 1. Age pattern

\begin{tabular}{c|c} 
Age group & Number \\
\hline $11-20$ & 09 \\
$21-30$ & 53 \\
$31-40$ & 64 \\
$41-50$ & 41 \\
$51-60$ & 30 \\
$61-70$ & 13 \\
$71-80$ & 5 \\
\hline Total & 215
\end{tabular}


The preoperative diagnosis was cancer in $67(31.2 \%)$ cases. Other diagnoses were abscess in 53; fibroadenoma in 43; suspicious tumours in 21; mammary dysplasia and galactocele in 10 each and cyst in 6 cases. Five cases were not classified.

The associated pathological conditions were almost always mammary dysplasia, to use one of the alternative names listed by Rosai ${ }^{4}$ in one patient, whereas both mammary dysplasia and fibroadenoma were found, but abscess formation was clearly linked with the dysplastic area.

\section{Discussion:}

It is acknowledged that the highest incidence of breast abscess occurs in lactating women $^{5}$. In this connection, it was argued by Adler $^{6}$ that one cause of this infection is fissuring of the nipple from which bacteria gain entry into the periglandular tissue, another cause is "missed or delayed feeding or attempted weaning, which leads to milk stasis and subsequent bacterial overgrowth and infection." Undoubtedly, these antecedents also prevail in the Igbo community. However, what about postmenopausal women? Unlike a West Indian report on the scarcity of post-menopausal abscess $^{2}$ Igbo patients aged over 50 years numbered up to $47(22.3 \%)$ while six were in their 70s. One possible reason for hospital attendance of such women is breast cancer awareness. Elsewhere, the author showed that such public awareness is manifested by the cases of fibroadenoma occurring among teenagers in the Igbo community ${ }^{7}$.

Cox's and colleagues ${ }^{8}$ were impressed by the fact that patients with either a lump, discharge from the nipple or pain in the breast represent a considerable work load at a general surgical clinic in England. In their series of 753 cases, there were only 7 patients with abscess, but their ages were not mentioned.

With particular regard to such abscess, its pathogenesis is linked with rupture of mammary ducts ${ }^{4}$. An American report showed $^{9}$ the non-lactating breast may also be the seat of abscess formation. Certainly, this is confirmed by its occurrence even after the menopause.

Does such abscess occur more often in West African than in West Indian postmenopausal women? In this connection, in a review that focused predominantly on bacterial infection in the elderly ${ }^{10}$ the respiratory tract, urinary tract, biliary tract, vagina, skin, joints, bone, brain, heart, liver, appendix, peritoneum, and parotid gland were discussed but not the breast. It is well, in consequence, to remember this important organ and to prosecute research on how epidemiologic factors influence tendency to infections. This is so especially with regard to women in the post-menopausal state. Recently, from Saudi Arabia ${ }^{11}$ out of 434 breast biopsies there were 47 abscesses, thus indicating that it is relatively common. Unfortunately, the age patterns were not documented.

\section{Acknowledgements:}

My thanks are due to all who helped me by way of sending reprints. Concerning the dispatched specimens, many clinicians were helpful. So were those who rendered technical and secretarial assistance.

\section{References:}

1. Onuigbo WIB. Analyzing medicine by means of reprint requests. Methods Inform Med 1985; 24: 37-39.

2. Raju GC, Naraynsingh V, Jankey N. Post-menopausal breast abscess. Postgrad Med J 1986; 62: 1017-1018.

3. Basden GT. Niger Ibos. 2nd Edition, London: Frank Cass \& Co. Ltd., 1966: 455 pages.

4. Rosai J. Ackerman's Surgical Pathology. 8th Edition, St Louis: Mosby-Year Book, Inc., 1996: pages 1569 and 1582.

5.Hughes LE. Classification of benign breast disorders. Br Med Bull 1991; 47: 251-257.

6. Adler HL. Breast infection. In: Meakins JL, ed. Surgical Infections. New York; Scientific American, Inc; 1994: 287.

7. Onuigbo WIB. Breast fibroadenoma in teenage females. Turk J Pediat 2003; 45: 326-328. 
8. Cox PJ, Li MKW, Ellis H. Spectrum of breast disease in outpatient surgical practice. J Roy Soc Med 1982; 75: 857859.

9. Ekland DA, Zeigler MG. Abscess in the non-lactating breast. Arch Surg 1973; 107: 398-401.
10. Smith IM. Infections in the elderly. Hosp Pract 1982; 17: 69-85.

11. Altaf FJ. Patterns of breast diseases: King Khalid National Guard Hospital experience. Ann Saudi Med 2001; 21: 239-241. 